\title{
Research Article \\ Understanding MOOC Reviews: Text Mining using Structural Topic Model
}

\author{
Xieling Chen ${ }^{1}$, Gary Cheng ${ }^{1, *}$, Haoran Xie ${ }^{2}$, Guanliang Chen $^{3}$, Di Zou ${ }^{4}$ \\ ${ }^{1}$ Department of Mathematics and Information Technology, The Education University of Hong Kong, New Territories, Hong Kong SAR, China \\ ${ }^{2}$ Department of Computing and Decision Sciences, Lingnan University, New Territories, Hong Kong SAR, China \\ ${ }^{3}$ Faculty of Information Technology, Monash University, Clayton, Australia \\ ${ }^{4}$ Department of English Language Education, The Education University of Hong Kong, New Territories, Hong Kong SAR, China
}

\section{ARTICLE INFO \\ Article History \\ Received 25 June 2021 \\ Accepted 17 November 2021 \\ Keywords \\ MOOC course reviews programming courses learner dissatisfaction structural topic model text mining}

\begin{abstract}
Understanding the reasons for Massive Open Online Course (MOOC) learners' complaints is essential for MOOC providers to facilitate service quality and promote learner satisfaction. The current research uses structural topic modeling to analyze 21,692 programming MOOC course reviews in Class Central, leading to enhanced inference on learner (dis)satisfaction. Four topics appear more commonly in negative reviews as compared to positive ones. Additionally, variations in learner complaints across MOOC course grades are explored, indicating that learners' main complaints about high-graded MOOCs include problemsolving, practices, and programming textbooks, whereas learners of low-graded courses are frequently annoyed by grading and course quality problems. Our study contributes to the MOOC literature by facilitating a better understanding of MOOC learner (dis)satisfaction using rigorous statistical techniques. Although this study uses programming MOOCs as a case study, the analytical methodologies are independent and adapt to MOOC reviews of varied subjects.
\end{abstract}

(C) 2021 The Authors. Publishing services by Atlantis Press International B.V.

This is an open access article distributed under the CC BY-NC 4.0 license (http://creativecommons.org/licenses/by-nc/4.0/).

\section{INTRODUCTION}

Learner satisfaction is increasingly concerned in distance education as a measure of learners' perception of Massive Open Online Courses (MOOC). Online reviews are commonly considered important to influence learners' decisions about whether or not to take an online course [1]. Particularly, negative reviews are more credible, altruistic, and influential as compared to positive ones [2]. Therefore, to improve MOOC learner satisfaction and reduce complaints, executives of MOOCs have become interested in studying topics within course reviews on MOOC platforms to investigate important MOOC features to learners.

Researchers have explored MOOC learner (dis)satisfaction determinants by analyzing online course reviews using manual coding and computer-aided approaches. Conclusions of manual coding approaches depend seriously upon coder expertise [3]. Such subjective biases lead to difficulties in result replication, and the limited sample sizes cause results to be less comprehensive. As such, computer-based text mining approaches like probabilistic topic models for textual course review analysis in MOOC learner (dis) satisfaction research are becoming increasingly important (e.g., $[4,5])$. However, the traditional way of applying topic models focuses primarily on negative reviews, leading to the potential danger of mixing the positive sides since reviewers usually do not complain from the beginning to the end in writing a negative

“Corresponding author.Email: chengks@eduhk.hk

Peer review under responsibility of KEO (Henan) Education Technology Co. Ltd review. Therefore, not all topics mentioned in negative reviews through topic models are true negative. To effectively understand causes for MOOC learner (dis)satisfaction, we ought to detect topics significantly appearing only or more in negative reviews as compared to positive ones. As such, the Structural Topic Model (STM) [6] is theoretically suitable since it allows researchers to include covariates that can affect topic distributions [7].

To that end, this study utilizes STM for MOOC review analysis. To demonstrate the methodological effect, we analyze 21,692 programing course reviews to determine the genuine determinants of programming MOOC learners' (dis)satisfaction and reveal the variations in learner complaints across courses with varied grades.

\section{LITERATURE REVIEW}

A number of studies (Table 1) explore MOOC learners' concerning issues based on manual content analysis or using computer-aided approaches (e.g., frequency analysis and topic modeling) or questionnaire surveys.

Manual content analysis is a common approach for identifying what learners concern about via textual course review analysis (e.g., [1,8]). For example, based on three top-ranked MOOCs, Hew et al. [8] identified factors, including (1) problem-driven learning, (2) lecture accessibility and enthusiasm, (3) active learning, (4) learner-learner interaction, and (5) resources and materials, that accounted for MOOC popularities. Based on manual coding of a sample of 8274 randomly selected MOOC 
Table 1 Research on the exploration of influential factors for MOOC learner satisfaction

\begin{tabular}{|c|c|c|c|}
\hline Study & Data source & Main findings & Methods \\
\hline Liu et al. [5] & $\begin{array}{l}\text { 12,524 reviews from } 50 \text { courses } \\
\text { in Guokr Web }\end{array}$ & $\begin{array}{l}\text { Topics with the positive (negative) sentiment: } \\
\text { course content (course logistics and video production) }\end{array}$ & Topic modeling \\
\hline Hew et al. [1] & $\begin{array}{l}\text { A random sample of } 8274 \text { reviews } \\
\text { in } 400 \text { MOOCs }\end{array}$ & $\begin{array}{l}\text { Significant factors affecting satisfaction: course } \\
\text { instructor, content, assessment, and schedule }\end{array}$ & Manual coding methods \\
\hline Peng and $\mathrm{Xu}[13]$ & $\begin{array}{l}775 \text { posts and } 165 \text { responses concerning } \\
\text { a course named "Financial Analysis } \\
\text { and Decision-making" }\end{array}$ & $\begin{array}{l}\text { Completers show positive sentiment toward } \\
\text { course-related content, and non-completers show } \\
\text { negative sentiment toward platform construction }\end{array}$ & Topic modeling \\
\hline Hew [8] & $\begin{array}{l}965 \text { reviews of three highly- } \\
\text { rated MOOCs }\end{array}$ & $\begin{array}{l}\text { Five influential factors: (1) problem-driven learning } \\
\text { with adequate explanations, (2) lecturer accessibility } \\
\text { and enthusiasm, (3) active learning, (4) learner-learner } \\
\text { interaction, and (5) resources and materials }\end{array}$ & Manual coding methods \\
\hline Ezen-Can et al. [14] & $\begin{array}{l}550 \text { posts from } 155 \text { learners for an } \\
\text { 8-week MOOC }\end{array}$ & $\begin{array}{l}\text { Seven clusters: (1) resources and learner achievement, } \\
\text { (2) personal ideas, (3) factual moves, resource access, } \\
\text { (4) classrooms, tools, and programs, (5) pedagogical } \\
\text { plans, (6) student learning, and (7) support and equity. }\end{array}$ & Topic modeling \\
\hline Peng et al. [15] & $\begin{array}{l}6163 \text { reviews of } 50 \text { highly-rated } \\
\text { courses in mooc.guokr.com }\end{array}$ & $\begin{array}{l}\text { Five significant topics: (1) learners' feelings and experiences } \\
\text { about MOOCs, (2) literature course named "A Dream } \\
\text { in Red Mansions," (3) discussion of architecture, } \\
\text { (4) basic knowledge of the introduction and planning } \\
\text { of marketing, and (5) historical course called "Records } \\
\text { of the Grand Historian." }\end{array}$ & Topic modeling \\
\hline Gameel [10] & $\begin{array}{l}1786 \text { questionnaires of } \\
\text { MOOCs learners }\end{array}$ & $\begin{array}{l}\text { Important factors affecting satisfaction: learner perceived } \\
\text { usefulness, instruction and learning aspects of MOOCs, } \\
\text { and learner-content interaction }\end{array}$ & $\begin{array}{l}\text { Questionnaire survey } \\
\text { and statistical analysis }\end{array}$ \\
\hline
\end{tabular}

course reviews, Hew et al. [1] identified course structure, videos, instructors, content and resources, interaction, and assessment as important factors affecting learner satisfaction. Although manual coding approaches have strong interpretation power guaranteed by well-designed frameworks, the reliability of coding results depends seriously upon analyst knowledge, and the coding process is laborious, leading to difficulties in result replication with limited samples [7,9].

There are also scholars exploring factors affecting MOOC learner satisfaction using questionnaire-based surveys alongside statistical methodologies like regression analysis. For example, by analyzing 1786 MOOC learners' questionnaires, Gameel [10] indicated the significant role of learner perceived usefulness and learner-content interaction in affecting MOOC learner satisfaction. Although findings from such questionnaire-based survey studies help understand MOOC learners' preferences and facilitate new MOOC design and development, only a limited amount of information is provided without explanation. Also, interviewers commonly have different interpretations of the same questions; therefore, subjectivities cannot be avoided. Additionally, potential researcher imposition may affect result efficacy since researchers usually make assumptions when developing questionnaires $[11,12]$.

In addition to manual coding methodologies and questionnairebased surveys, a mainstream of automatic text mining approaches for MOOC learner satisfaction research is topic modeling [4,5, 13-15]), which, with the basis of term co-occurrence, have topics (i.e., a collection of terms with high co-occurrence probabilities) as outputs [16,17]. A topic modeling analysis of 50 MOOCs [5] indicates that "learners focus more on course-related content with positive sentiment and course logistics and video production with negative sentiment (p. 670)." Although such analyses enhance our understanding of important topics that are frequently mentioned by learners, no study focuses on identifying topics appearing significantly more frequently in negative reviews as compared to positive ones.

Results regarding influential factors of learner satisfaction in the existing studies varied. For example, according to Liu et al. [5], learners complained more about course logistics and video production. Hew et al. [1] indicated the significant effects of the course instructor, content, assessment, and schedule on learner satisfaction. Peng and $\mathrm{Xu}$ [13] concluded that non-completers were likely to show negative sentiment toward platform construction. Considering the inconsistent findings and the research gap that no study compares positive and negative reviews by adopting topic models, we contribute to MOOC learner satisfaction literature by (1) uncovering topics that frequently appear in negative reviews, and (2) exploring differences in learner complaints among courses with varied grades.

\section{DATA AND MODEL SETUP}

\subsection{Data Collection and Preprocessing}

The programming MOOC reviews were obtained from Class $\mathrm{Central}^{1}$ on 5th June 2020. By further eliminating duplicated MOOCs and those without reviews, 934 MOOCs remained. The course metadata and review data of these MOOCs were automatically crawled. A total of 25,694 review comments were collected. After excluding reviews without providing useful information concerning specific aspects of MOOC courses (e.g., "A completed this

${ }^{1}$ https://www.class-central.com/. 
course" and "Very good") and non-English ones, 25,135 reviews remained.

Among the 25,135 reviews, 5-, 4-, 3-, 2-, and 1-point ratings were $88.42 \%, 12.61 \%, 1.66 \%, 0.70 \%$, and $0.76 \%$, respectively (Table 2 ). To deal with the unbalanced rating distribution, we followed the strategy in $\mathrm{Hu}$ et al. [7] to define negative reviews as those with 1- or 2-point ratings, and 5-point rating reviews were treated as positive ones. Lastly, 21,692 reviews for 304 courses were used for topic modeling and analysis.

For the 21,692 reviews, terms were extracted using Natural Language Tool Kit (NLTK), ${ }^{2}$ with which word normalization and exclusion of default stop-words (e.g., "the" and "is"), punctuations, and numbers were conducted. Second, terms that were written in British and American English (e.g., "analyze" and "analyse;" "beginner" and "beginner") were manually unified. Third, user-defined stop-words such as "everything," "everyone," and "everybody" were excluded. Fourth, manual stemming, that is, converting terms to root forms (e.g., "automate," "automatic," and "automation" were converted to "automat"), was conducted. Also, misspellings and non-words were excluded (e.g., "x2," "x27," “Xavier," “xc," “xd," “xi-xii," “x-mas," “yh,” “yo," and “y-o"). Furthermore, terms that represent the names of a person or course were excluded to reduce noise. In addition, we filtered unimportant terms with a term frequency-inverse document frequencies value of not more than 0.03 .

\subsection{STM Model Setup}

In STM, each topic and document is assumed to be a distribution of terms and a mixture of topics, respectively. With a significant improvement over Latent Dirichlet Allocation, STM allows examining how document-level structure information affects topic prevalence and content. Figure 1 presents the plate diagram of STM, in which nodes are variables with labels indicating their roles in the modeling process. The unshaded (shaded) nodes represent hidden (observed) variables. Rectangles indicate replication: $n \in\{1,2, \ldots, N\}$ indexes terms in each document; $k \in$ $\{1,2, \ldots, K\}$ indexes each topic supposing $K$ topics; and $d \in\{1$, $2, \ldots, D\}$ indexes documents. STM aims to understand the unseen

Table 2 Statistics of the included reviews

\begin{tabular}{lcc}
\hline Items & Frequency & $\%$ \\
\hline Distribution of course grade & \\
Grade 1 & 8 & 2.63 \\
Grade 2 & 14 & 4.61 \\
Grade 3 & 35 & 11.51 \\
Grade 4 & 89 & 29.28 \\
Grade 5 & 158 & 51.97 \\
Distribution of rating & \\
Grade 1 & 183 & 0.76 \\
Grade 2 & 168 & 0.70 \\
Grade 3 & 400 & 1.66 \\
Grade 4 & 3,043 & 12.61 \\
Grade 5 & 21,341 & 88.42 \\
\hline
\end{tabular}

${ }^{2}$ https://www.nltk.org/. topics based on the observable terms, $W$, and generates two matrices, that is, document-topic distributions $\theta$ and topic-term distributions $\beta$.

Taking advantage of STM's ability to add topic prevalence parameters to influence a document's distribution over topics, we modeled the impact of review extremity (positivity and negativity), course grade, and their interactions on topic prevalence $\mu$, which further determines document-topic distribution $\theta$. To explore how document-level covariates influenced topic prevalence, Negative and CourseGrade were defined as covariates to indicate review orientation and course ratings separately. Negative equals 1 for negative reviews with 1 - and 2 -point ratings, and 0 for positive reviews with 5-point ratings. CourseGrade ranges from 1 to 5 . The relationship between topic prevalence and covariates is indicated by Prevalence $=g($ Negative, CourseGrade, Negative $\times$ CourseGrade $)$, where $g(\bullet)$ represents a generalized linear function.

A key step in STM is to choose the number of topics K. Such a task was performed by using both quantitative and qualitative techniques. Specifically, from the quantitative perspective, we proceeded by estimating various models with varied numbers of topics (i.e., from five to 30). We compared the estimated models using their scores on average semantic coherence and exclusivity $[7,18]$ (Figure 2), two popular indexes in topic modeling for an initial selection of the input number of topics. Three models ( $K=14,15$, and 16$)$ outperformed others and were selected for

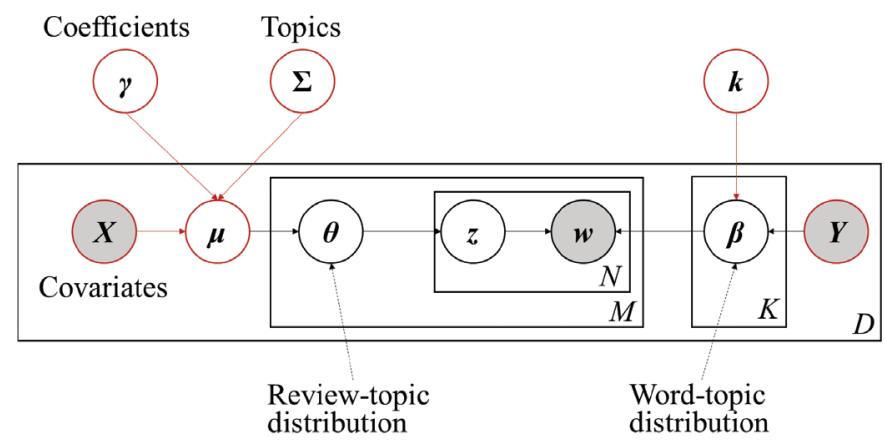

Figure 1 Plate diagram of STM.

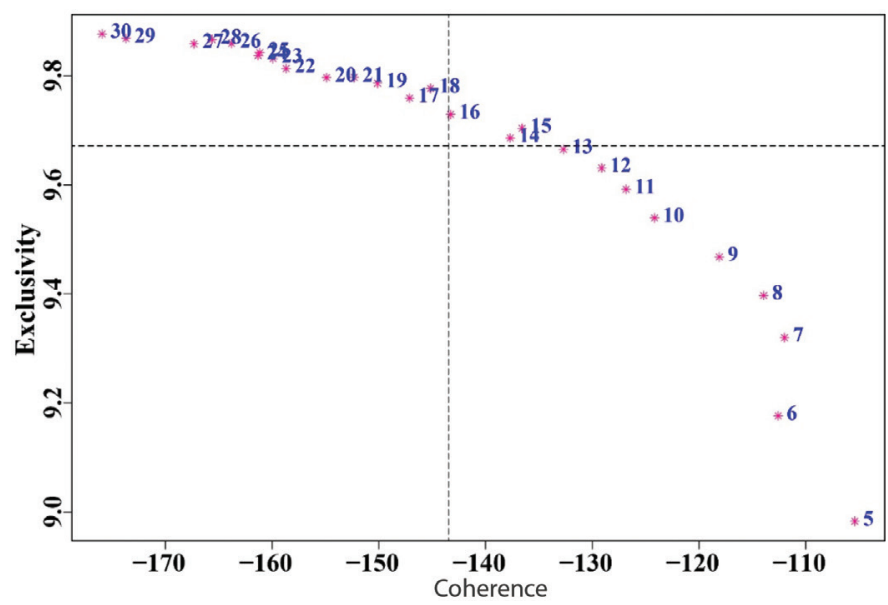

Figure 2 Model diagnosis using exclusivity and coherence. 
further comparison. From the qualitative perspective, each of the two domain experts carefully compared the three models through examining terms and review comments based on four criteria. First, top terms in each topic together produced an important topic related to MOOC learning. Second, top review comments for each topic were representable. Third, no overlaps between topics within a model were found. In addition, as many important topics related to MOOC learning as possible were included in a single model. Both experts identified the model with 14 topics as the one that produced "the greatest semantic consistency within topics, as well as exclusivity between topics (p. 4) [3]." Thus, by using both the quantitative and qualitative techniques, we finalized to use the model with 14 topics. For each estimated topic, we examined closely the 20 terms and reviews that featured it most and assigned names to each topic accordingly.

\section{RESULTS}

\subsection{Frequently used Terms in Negative and Positive Reviews}

Figure $3 \mathrm{a}$ and $3 \mathrm{~b}$ present the word cloud visualization of the frequently used terms in positive and negative reviews, respectively (also see Tables 3 and 4). There are more positive terms commonly used in positive reviews, for example, "easy," "basic," "helpful," "simple," "interest," "enjoy," "clear," and "complete." On the contrary, negative reviews tend to use more negative terms, for example, "bad," "difficult," “disappoint," "wrong," "fail," and "poor." In addition, in positive reviews, the common issues are "beginner," "material," "concept," "assignment," "knowledge," "code," and "professor," whereas in negative reviews, issues concerning "quiz," "code," "example," "assignment," "video," "instructor," “content," "concept,"

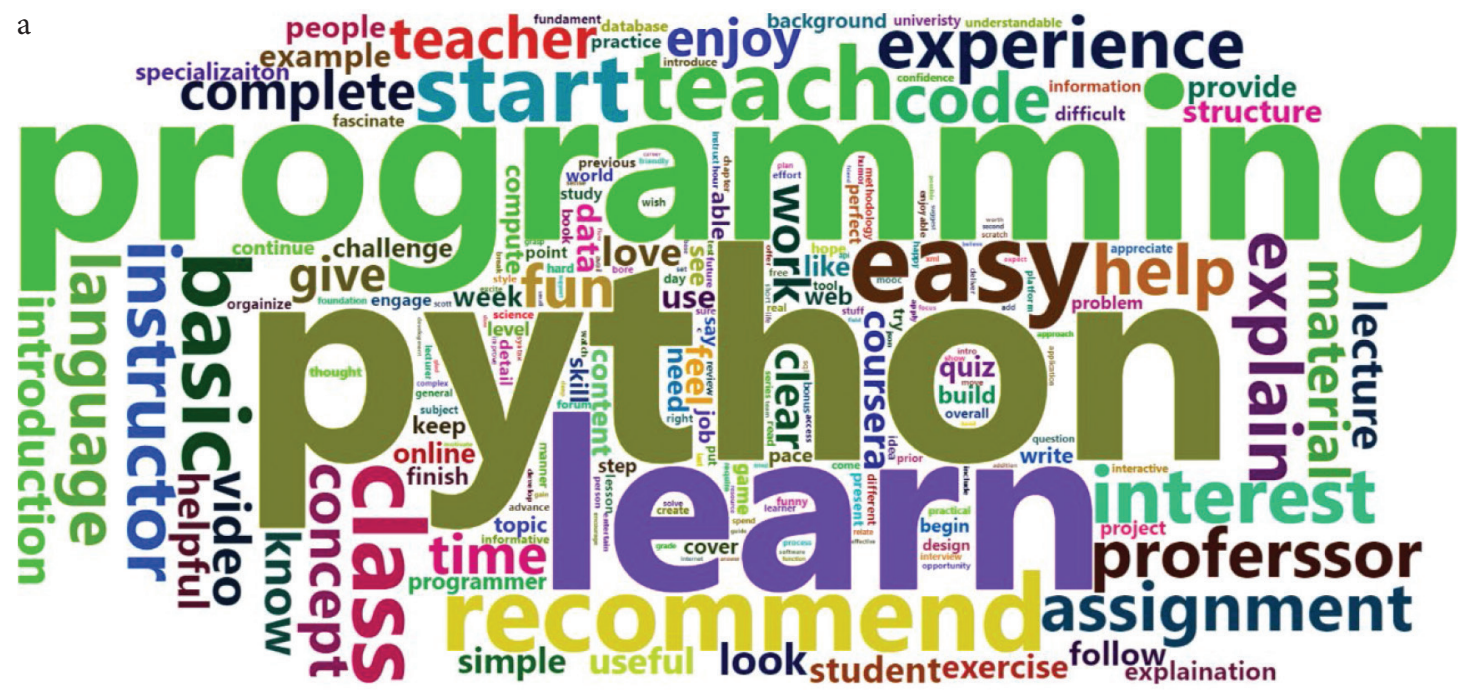

b

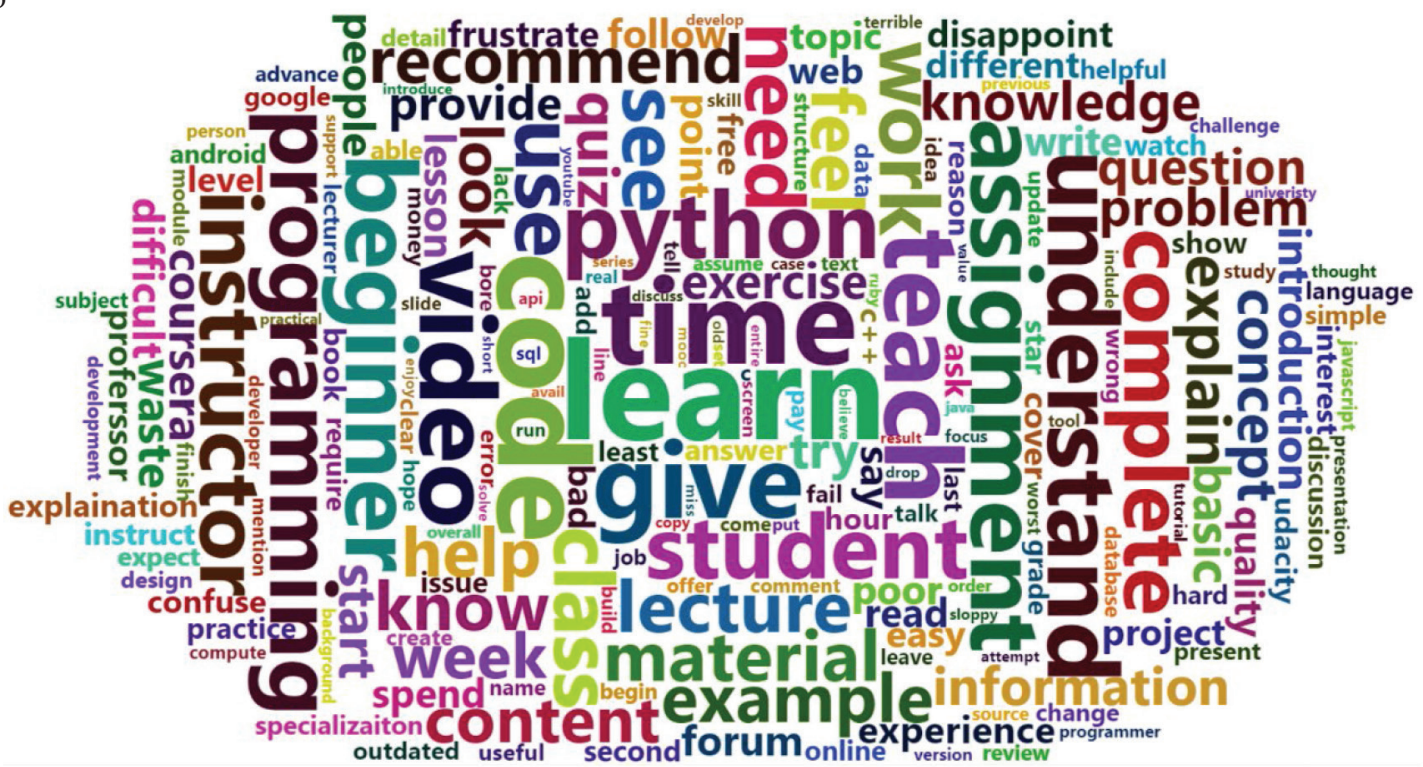

Figure 3 Frequently used terms in (a) positive reviews (term frequency >=200) (download the dynamic map via https://drive.google.com/file/ $\mathrm{d} / 1$ CdD7otd4zT5UKUTZmCKr6ay_sjtqwvYI/view? usp=sharing) and (b) negative reviews (term frequency $>=10$ ) (download the dynamic map via https://drive.google.com/file/d/1E3A7my0QLcBZ54av92RABvavrnlBV8_v/view? usp=sharing). 
Table 3 Frequently used terms in positive reviews

\begin{tabular}{|c|c|c|c|c|c|c|c|c|}
\hline Word & $F$ & $\%$ & Word & $F$ & $\%$ & Word & $F$ & $\%$ \\
\hline python & 10,120 & 47.42 & follow & 1131 & 5.30 & database & 547 & 2.56 \\
\hline learn & 8206 & 38.45 & structure & 1122 & 5.26 & design & 523 & 2.45 \\
\hline programming & 7680 & 35.99 & people & 1072 & 5.02 & present & 515 & 2.41 \\
\hline easy & 4007 & 18.78 & provide & 1040 & 4.87 & organize & 511 & 2.39 \\
\hline recommend & 3688 & 17.28 & content & 1016 & 4.76 & hope & 508 & 2.38 \\
\hline beginner & 3675 & 17.22 & week & 990 & 4.64 & university & 500 & 2.34 \\
\hline understand & 3641 & 17.06 & need & 982 & 4.60 & book & 491 & 2.30 \\
\hline teach & 3516 & 16.48 & like & 969 & 4.54 & previous & 488 & 2.29 \\
\hline class & 3498 & 16.39 & quiz & 969 & 4.54 & overall & 473 & 2.22 \\
\hline start & 3370 & 15.79 & online & 965 & 4.52 & thought & 470 & 2.20 \\
\hline basic & 3239 & 15.18 & challenge & 916 & 4.29 & lesson & 467 & 2.19 \\
\hline interest & 2728 & 12.78 & see & 911 & 4.27 & understandable & 451 & 2.11 \\
\hline instructor & 2541 & 11.91 & compute & 903 & 4.23 & day & 445 & 2.09 \\
\hline explain & 2537 & 11.89 & explanation & 893 & 4.18 & fundament & 444 & 2.08 \\
\hline experience & 2472 & 11.58 & web & 858 & 4.02 & tool & 442 & 2.07 \\
\hline help & 2411 & 11.30 & skill & 848 & 3.97 & manner & 436 & 2.04 \\
\hline code & 2383 & 11.17 & able & 838 & 3.93 & hard & 435 & 2.04 \\
\hline assignment & 2375 & 11.13 & specialization & 830 & 3.89 & put & 432 & 2.02 \\
\hline professor & 2354 & 11.03 & finish & 829 & 3.88 & appreciate & 431 & 2.02 \\
\hline language & 2324 & 10.89 & build & 828 & 3.88 & different & 430 & 2.01 \\
\hline knowledge & 2080 & 9.75 & keep & 827 & 3.88 & idea & 430 & 2.01 \\
\hline teacher & 2046 & 9.59 & programmer & 799 & 3.74 & read & 429 & 2.01 \\
\hline fun & 2030 & 9.51 & topic & 771 & 3.61 & informative & 428 & 2.01 \\
\hline concept & 1977 & 9.26 & job & 766 & 3.59 & science & 416 & 1.95 \\
\hline material & 1954 & 9.16 & write & 759 & 3.56 & forum & 411 & 1.93 \\
\hline time & 1925 & 9.02 & background & 734 & 3.44 & introduce & 407 & 1.91 \\
\hline complete & 1850 & 8.67 & cover & 731 & 3.43 & right & 398 & 1.86 \\
\hline video & 1801 & 8.44 & pace & 701 & 3.28 & real & 396 & 1.86 \\
\hline enjoy & 1795 & 8.41 & continue & 687 & 3.22 & funny & 395 & 1.85 \\
\hline work & 1739 & 8.15 & project & 683 & 3.20 & methodology & 393 & 1.84 \\
\hline introduction & 1695 & 7.94 & step & 674 & 3.16 & create & 391 & 1.83 \\
\hline give & 1687 & 7.90 & game & 673 & 3.15 & wish & 389 & 1.82 \\
\hline know & 1679 & 7.87 & level & 670 & 3.14 & subject & 387 & 1.81 \\
\hline lecture & 1598 & 7.49 & say & 670 & 3.14 & interactive & 386 & 1.81 \\
\hline clear & 1531 & 7.17 & difficult & 651 & 3.05 & come & 385 & 1.80 \\
\hline look & 1469 & 6.88 & practice & 650 & 3.05 & prior & 382 & 1.79 \\
\hline helpful & 1438 & 6.74 & begin & 640 & 3.00 & review & 381 & 1.79 \\
\hline love & 1397 & 6.55 & problem & 616 & 2.89 & confidence & 378 & 1.77 \\
\hline coursera & 1368 & 6.41 & perfect & 607 & 2.84 & bonus & 376 & 1.76 \\
\hline useful & 1270 & 5.95 & world & 605 & 2.83 & style & 369 & 1.73 \\
\hline student & 1256 & 5.89 & engage & 602 & 2.82 & advance & 364 & 1.71 \\
\hline feel & 1203 & 5.64 & detail & 601 & 2.82 & series & 364 & 1.71 \\
\hline simple & 1203 & 5.64 & fascinate & 589 & 2.76 & future & 362 & 1.70 \\
\hline use & 1181 & 5.53 & try & 588 & 2.76 & effort & 361 & 1.69 \\
\hline exercise & 1159 & 5.43 & point & 577 & 2.70 & general & 360 & 1.69 \\
\hline data & 1154 & 5.41 & information & 563 & 2.64 & chapter & 359 & 1.68 \\
\hline example & 1136 & 5.32 & study & 556 & 2.61 & practical & 357 & 1.67 \\
\hline
\end{tabular}

$F$, frequency.

"python," "material," "quality," "explain," "exercise," and "time," are mentioned more frequently.

\subsection{Topic Summary and Validation}

Table 5 displays the topic modeling results. The first column shows the labels that briefly summarize the meaning of each topic. The second column presents the top terms having the highest frequencies and exclusivities of each topic. The third column indicates topic prevalence. The most concerning topic is learner friendliness, followed by solution explanation, learning perception, learning attitude, and course interactivity and difficulty.

\subsection{Identification of Negative Topics}

Figure 4 visualizes the relative topic prevalence in positive and negative reviews, where dots are "the mean values of the estimated differences and the bars are $95 \%$ confidence intervals for the difference (p. 422) [7]." The results evidently show four negative topics, including grading, problem solving and practices, course quality, and programming textbooks. We also provide examples of representative reviews for each negative topic (Table 6).

The top negative topic is grading with representative words such as "grade," "question," "wrong," "distract," "autograde," "mark," "answer," and "check." The examination of representative reviews indicates that the topic is commonly associated with technical 
Table 4 Frequently used terms in negative reviews

\begin{tabular}{|c|c|c|c|c|c|c|c|c|}
\hline Word & $F$ & $\%$ & Word & $F$ & $\%$ & Word & $F$ & $\%$ \\
\hline learn & 89 & 25.36 & provide & 31 & 8.83 & second & 19 & 5.41 \\
\hline code & 83 & 23.65 & waste & 31 & 8.83 & watch & 19 & 5.41 \\
\hline time & 78 & 22.22 & introduction & 29 & 8.26 & add & 18 & 5.13 \\
\hline teach & 70 & 19.94 & people & 29 & 8.26 & discussion & 18 & 5.13 \\
\hline give & 69 & 19.66 & difficult & 28 & 7.98 & grade & 18 & 5.13 \\
\hline video & 69 & 19.66 & lesson & 28 & 7.98 & last & 18 & 5.13 \\
\hline assignment & 64 & 18.23 & forum & 27 & 7.69 & least & 18 & 5.13 \\
\hline beginner & 64 & 18.23 & point & 27 & 7.69 & online & 18 & 5.13 \\
\hline understand & 64 & 18.23 & say & 27 & 7.69 & require & 18 & 5.13 \\
\hline python & 61 & 17.38 & follow & 26 & 7.41 & able & 17 & 4.84 \\
\hline programming & 60 & 17.09 & poor & 26 & 7.41 & android & 17 & 4.84 \\
\hline student & 58 & 16.52 & quality & 26 & 7.41 & data & 17 & 4.84 \\
\hline complete & 57 & 16.24 & read & 26 & 7.41 & expect & 17 & 4.84 \\
\hline instructor & 57 & 16.24 & spend & 26 & 7.41 & google & 17 & 4.84 \\
\hline use & 56 & 15.95 & write & 26 & 7.41 & hard & 17 & 4.84 \\
\hline class & 54 & 15.38 & easy & 25 & 7.12 & helpful & 17 & 4.84 \\
\hline need & 53 & 15.10 & experience & 25 & 7.12 & lack & 17 & 4.84 \\
\hline see & 53 & 15.10 & topic & 25 & 7.12 & simple & 17 & 4.84 \\
\hline work & 53 & 15.10 & web & 25 & 7.12 & specialization & 17 & 4.84 \\
\hline feel & 47 & 13.39 & bad & 24 & 6.84 & change & 16 & 4.56 \\
\hline lecture & 47 & 13.39 & different & 24 & 6.84 & clear & 16 & 4.56 \\
\hline material & 46 & 13.11 & disappoint & 24 & 6.84 & detail & 16 & 4.56 \\
\hline example & 44 & 12.54 & frustrate & 24 & 6.84 & error & 16 & 4.56 \\
\hline help & 44 & 12.54 & project & 24 & 6.84 & fail & 16 & 4.56 \\
\hline know & 44 & 12.54 & ask & 23 & 6.55 & language & 16 & 4.56 \\
\hline recommend & 43 & 12.25 & level & 23 & 6.55 & lecturer & 16 & 4.56 \\
\hline content & 42 & 11.97 & professor & 23 & 6.55 & money & 16 & 4.56 \\
\hline week & 41 & 11.68 & cover & 22 & 6.27 & outdated & 16 & 4.56 \\
\hline explain & 40 & 11.40 & free & 22 & 6.27 & pay & 16 & 4.56 \\
\hline look & 39 & 11.11 & confuse & 21 & 5.98 & present & 16 & 4.56 \\
\hline quiz & 38 & 10.83 & explanation & 21 & 5.98 & talk & 16 & 4.56 \\
\hline concept & 37 & 10.54 & answer & 20 & 5.70 & wrong & 16 & 4.56 \\
\hline knowledge & 35 & 9.97 & book & 20 & 5.70 & $\mathrm{c}$ & 15 & 4.27 \\
\hline information & 34 & 9.69 & $\mathrm{c}++$ & 20 & 5.70 & create & 15 & 4.27 \\
\hline problem & 34 & 9.69 & hour & 20 & 5.70 & design & 15 & 4.27 \\
\hline start & 34 & 9.69 & instruct & 20 & 5.70 & finish & 15 & 4.27 \\
\hline basic & 33 & 9.40 & interest & 20 & 5.70 & idea & 15 & 4.27 \\
\hline question & 33 & 9.40 & reason & 20 & 5.70 & structure & 15 & 4.27 \\
\hline try & 33 & 9.40 & show & 20 & 5.70 & update & 15 & 4.27 \\
\hline exercise & 32 & 9.12 & star & 20 & 5.70 & useful & 15 & 4.27 \\
\hline coursera & 31 & 8.83 & udacity & 20 & 5.70 & advance & 14 & 3.99 \\
\hline issue & 19 & 5.41 & practice & 19 & 5.41 & begin & 14 & 3.99 \\
\hline
\end{tabular}

$F$, frequency.

Table 5 Topic summary

\begin{tabular}{llc}
\hline Labels & Representative terms & $\%$ \\
\hline learner friendliness & understandable, basic, prior, friendly, beginner, suitable, logic & 17.23 \\
solution explanation & easy, concept, explain, clear, exercise, digest, precise & 12.49 \\
learning perception & interest, cool, python, master, useful, well-structured, pleasure & 10.44 \\
learning attitude & enjoy, feel, complete, pace, comfortable, passionate, fun & 8.17 \\
course interactivity and difficulty & simple, confidence, interactive, help, lock-down, scratch, join & 7.73 \\
learning motivation and engagement & game, humor, willing, engage, bore, motivate, informative & 6.51 \\
learning experience & continue, excite, slow, worry, experience, fascinate, refresh & 5.96 \\
programming style and skill & session, style, brilliance, idle, software, breakpoints, cpu & 5.20 \\
IT infrastructure for MOOCs & database, sql, db, module, flow, control, dictionary & 5.09 \\
grading & grade, question, wrong, autograde, mark, answer, check & 5.07 \\
programming project & xml, json, api, html, parse, project, network, mini & 4.87 \\
problem solving and practices & solve, balance, homework, encounter, practical, real, mistake & 4.05 \\
programming textbooks & compute, describe, section, science, textbook, home & 3.67 \\
course quality & outstanding, key, limit, perspective, quality, link, rich & 3.52 \\
\hline
\end{tabular}


issues concerning submission, file uploading, website execution, and grader settings, as well as issues concerning unfair or error in grading and not available for trying again.

The second most negative topic is problem solving and practices. The associated complaints mainly center around classroom time arrangement, ambiguous wording of problems, and inappropriate difficulty level of exercises (either too difficult or pointless). Also, there are many learners complaining that they have to upgrade (to paid accounts) to complete quizzes. Furthermore, some learners

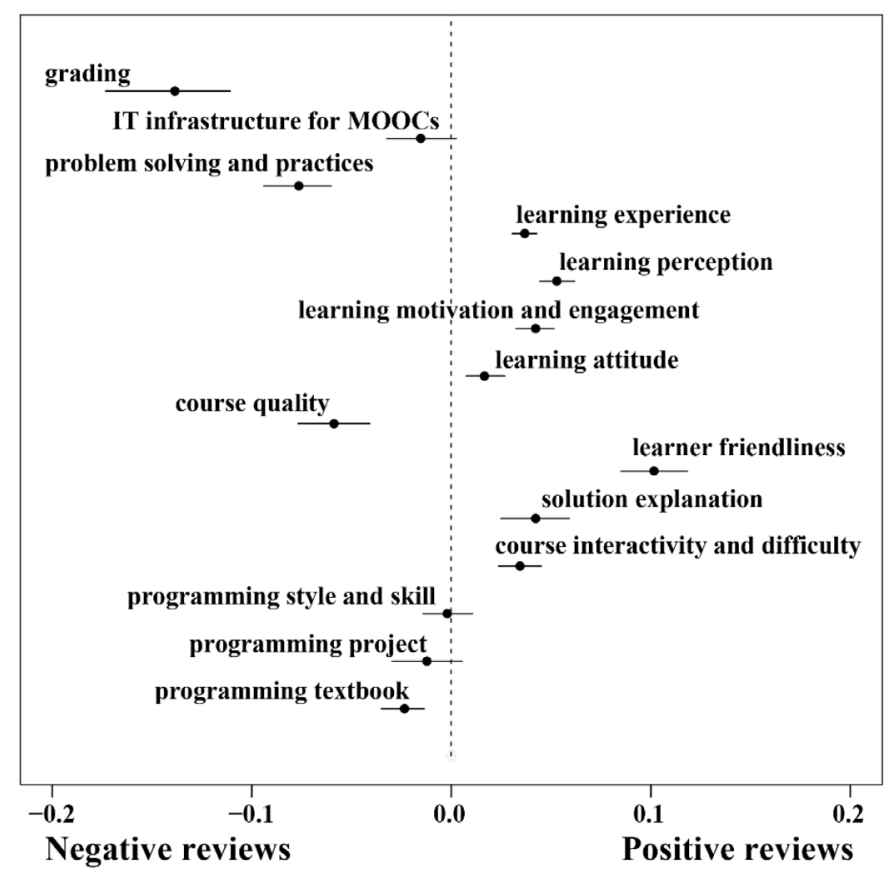

Figure 4 Differences in the topic prevalence (negative reviews versus positive reviews). point out that instructors' tips about practices are often too general and not helpful. Additionally, many learners complain that there are ambiguous quiz questions without explicit explanation.

The third topic is course quality with representative reviews commonly linked with an amateurish presentation, sloppy codes, poor and limited code examples, misleading and wrong information, unnecessary repetition, as well as incorrect or insufficient explanations of important concepts and functions, which fails to convey them in a concise and easy-to-understand format for beginners. In addition, there are learners complaining about broken links, especially "more info" links that just go to visual studio home pages where there are more advertisements than information.

The fourth topic is programming textbooks, where learners mainly complain that (1) chapters in textbooks are too brief, (2) textbooks are less useful while doing homework, (3) textbooks are extremely theoretical with no real-world information, and (4) much of the content is over-simplified to the point of ridiculous.

Results of the negative topic identification offer insights into factors accounting for MOOC learner satisfaction toward programming courses. Learners can be easily impressed by courses that are learnerfriendly, especially for beginners. Furthermore, most learners are satisfied with the content and materials with moderate difficulty. In addition, instructors' clear explanation of solutions and their interaction with learners can motive learner engagement.

\subsection{Topic Correlation Analysis}

The topic correlation [19] in Figure 5 intuitively indicates the essence of MOOC learner (dis)satisfaction. In the figure, topics are represented as nodes, and two nodes with high co-occurrence probabilities are linked. A shorter link between two nodes indicates a closer correlation. The sizes of nodes indicate their prevalences in the corpus. The colors of nodes indicate topic extremities, where

Table 6 Examples of representative reviews for negative topics

\begin{tabular}{|c|c|}
\hline Negative topics & Examples of reviews \\
\hline grading & $\begin{array}{l}\text { "You can't submit quizzes to see if you got them right, and all your coding problems are marked wrong. You can still do } \\
\text { the coding, and the website will error check and all, but you won't get the pass/fail grade to be sure you got it right." } \\
\text { "If using any new version of ruby or rails, you will have to modify multiple items in your files/system to get the grader } \\
\text { to work." } \\
\text { "I would have given } 5 \text { stars but my assignment has not got a fair marks. And I am not passed due to that grading." }\end{array}$ \\
\hline problem solving and practices & $\begin{array}{l}\text { "The time stated to complete the course was } 4-6 \text { h per week. With the lectures at } 1-2 \mathrm{~h} \text { per week, that left } 3-4 \mathrm{~h} \text { to } \\
\text { complete the homeworks.....not a chance." } \\
\text { "The wording of the problems too ambiguous; maybe that is the CS style? Some of the exercise seemed quite pointless. } \\
\text { Inconsistent level of difficulty. The last few problems required one to look for general patterns to code." } \\
\text { "You have to upgrade (to paid account) in order to complete quizzes. It's very unfortunate." } \\
\text { "Course is practically unuseful without exercises. Verified certificates cost money and it does mean students who not } \\
\text { pay can not practice." }\end{array}$ \\
\hline course quality & $\begin{array}{l}\text { "This course covers many important aspects of the JavaScript syntax, but ultimately fails to convey them in a concise } \\
\text { and easy-to-understand format that should be the basis of a beginner's class." } \\
\text { "I am an experienced programmer and teacher of programming. I started this course because I thought - reasonably, } \\
\text { given the title- that the course would get right to C++. Instead, there's a great deal of C and basic algorithms. This is } \\
\text { a waste of my time!" }\end{array}$ \\
\hline programming textbook & $\begin{array}{l}\text { "In general, the course is all like reading out loud the textbook." } \\
\text { "The textbook was not that helpful when it came to the homework problems." } \\
\text { "The chapters in the Think Python textbook are too brief." } \\
\text { "I am at home i have a kid so i was unable to study and doing the assignments in time." }\end{array}$ \\
\hline
\end{tabular}


the bluer (redder) colors indicate higher negativities (positivities). Topics of the same color tend to link closely, while topics of varied colors are commonly disconnected. For example, grading is closely associated with problem solving and practices, programming projects, programing style and skill, course quality, and programming textbooks, indicating that learners who write about grading issues tend to complain as well about programing issues, practices, and course quality. Such graphical topic correlation analysis enhances our understanding of possible causalities for MOOC learner dissatisfaction.

\subsection{The Moderating Effect of Course Grades}

Given the interaction term of Negative with CourseGrade in our model, we examined the variations in negative topics' proportions across course grades (Figure 6), with the $x$ - and $y$ axes indicating course grades and expected topic proportions, respectively. The blue and red lines represent negative and positive reviews, separately, with dashed lines depicting the 95\% confidence interval.

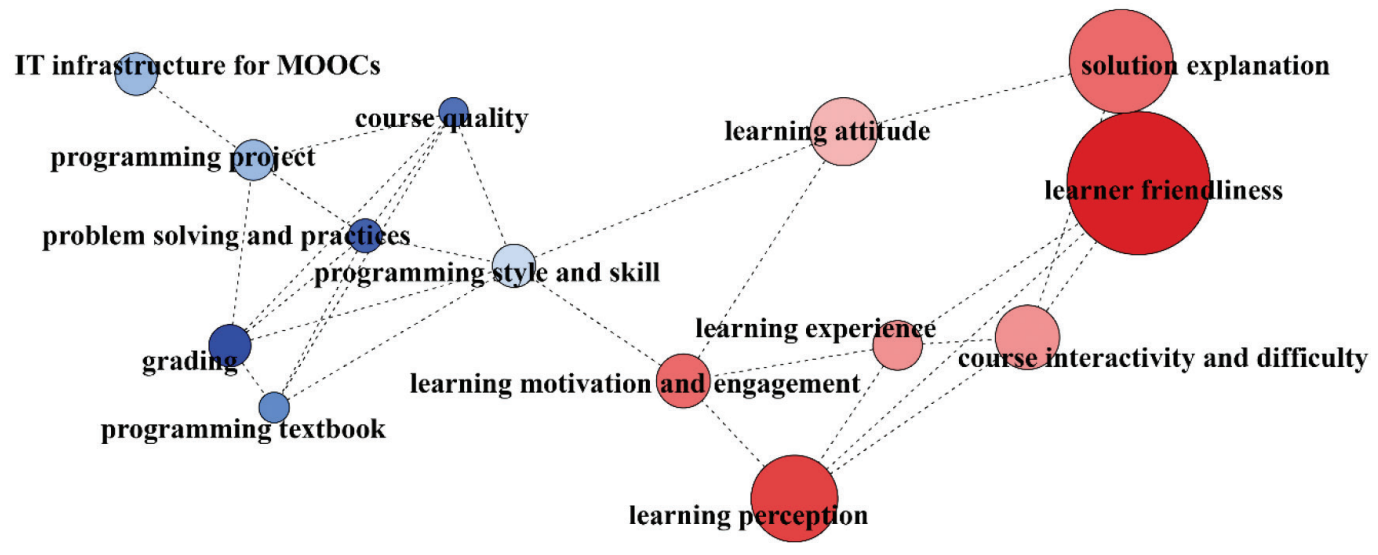

Figure 5 Graphical topic correlations.
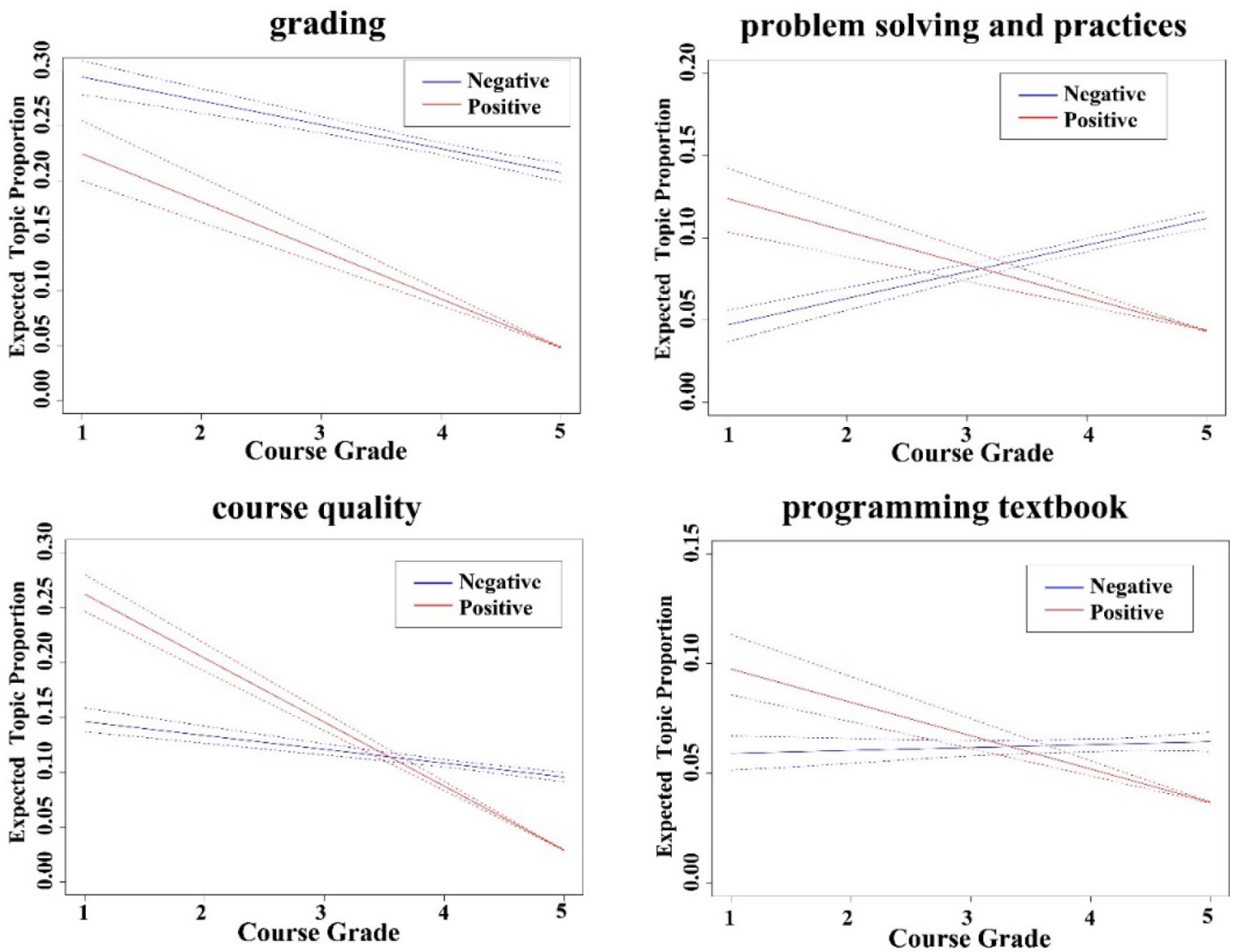

Figure 6 Moderating effects of course grades. 
Results indicate that the popularities of two negative topics (problem solving and practices and programming textbooks) in negative reviews increase alongside the increased course grades. For example, regarding problem solving and practices, its popularity in negative reviews increases significantly from about 5\% (CourseGrade $=$ one) to $10 \%$ (CourseGrade = five). On the contrary, its popularity in positive reviews experiences a significant decrease alongside the increased course grades. The popularities of the other two negative topics (i.e., grading and course quality) in the negative reviews decrease alongside the increased course grades. For example, the popularity of course quality in negative reviews decreases from about 25\% (CourseGrade = one) to $5 \%$ (CourseGrade = five).

The above results indicate that the major sources of MOOC learners' dissatisfaction are issues concerning grading, practices, and textbooks. For high-graded courses, problem-solving and practices and programming textbooks are the main causes for learner dissatisfaction, while for low-graded courses, grading and course quality are the primary causes.

\section{DISCUSSION AND CONCLUSION}

This first in-depth study applies STM on MOOC learner reviews to explore the major causes for learner complaints. We identified two most frequently mentioned topics (i.e., learner friendliness and solution explanation) and four negative topics (i.e., grading, problem solving and practices, course quality, and programming textbook design) appearing significantly more in negative reviews as compared to positive ones in statistics. Such analysis contributes to MOOC learner dissatisfaction literature by allowing learners' true complaints to be heard. The followings are discussions of the above six topics, based on which we provide suggestions to MOOC providers and lecturers to promote learner satisfaction.

Learner friendliness, which may involve system/service use and content learning, is the top factor mentioned by learners. A possible reason is that most learners use MOOCs for self-learning of programing. Thus, courses that provide basic programing knowledge are more suitable and are perceived as satisfactory among learners. Another possible explanation is that learners might have inadequate experience in MOOC learning and are unfamiliar with MOOC environments. Thereby, not all learners are skillful or capable of fully utilizing MOOC functionalities and services, leading to fear in MOOC use [20] and thus lower satisfaction.

Grading is another essential factor that affects learners' satisfaction toward MOOC learning. Such a result is consistent with the finding of Ramesh et al. [21]. To improve learners' satisfaction toward grading, technicians should pay attention to submission, file uploading, website execution, and grader settings to provide pleasant experiences for learners in dealing with assignments. Second, automatic graders' precision can be improved by using advanced deep learning algorithms to avoid unfairness or errors in grading. Additionally, retrying opportunities can be provided to learners.

Similar to Chen et al. [22] and Hew [23], we found that problemsolving is frequently mentioned in negative reviews. The following improvements can be considered. First, problems should be clearly expressed using precise rather than ambiguous wording. Second, the difficulty level of problems and practices should be adjusted appropriately to suit the course level. Furthermore, enough support from instructors should be provided to learners in solving problems, where instructors ought to be always available in discussion forums to answer learners' questions and give specific rather than general tips. Also, questions should be switched at moderate speed to allow enough time for learners to think and answer. In addition, solution explanation, as a top concern among MOOC learners, should also be carefully considered during instructors' problem-solving for learners. This is in line with Hew [8] that highlights the significance of problem-centered learning with clear expositions for engagement promotion in online courses. In programing learning, practical coding tasks and activities are commonly included to promote learners' understanding of concepts and knowledge. A problem-centered instructional strategy thus focuses on teaching learners concepts and skills via solving realworld tasks and problems. This is usually realized by instructors through performing simple tasks and offering explicit explanations and step-by-step instructions of specific coding procedures and relevant examples and non-examples of concepts. For example, for building an interactive game, instructors should specifically organize courses to assist learners in learning required concepts. Such procedure essentially contributes to bringing tangible meanings to the concepts and principles learned and motivates learners' learning interests.

Course quality is also identified to have a significant effect on learner satisfaction. Such a finding is consistent with previous studies (e.g., [24-26]), all of which indicated course quality as a key factor contributing to MOOC's successful execution. For example, Albelbisi [24] found that course quality significantly influenced learners' satisfaction in MOOC learning. Yang et al. [25] identified course quality as an essential factor to gauge MOOC success. Such a result provides evidence that courses with higher quality usually contribute to higher MOOC learners' satisfaction. The quality of MOOC courses, for example, design, output appropriateness, content, and ease of course material understanding, influences learner satisfaction and MOOC success. To improve course quality, sufficiently high-quality code examples should be provided to enhance learners' understanding of particular knowledge points. Also, instructors should provide sufficient explanations of important concepts and functions but avoid unnecessary repetitions of simple knowledge points. Furthermore, course content should be designed to suit target learners. For example, for basic courses, the content should be conveyed in a concise and easy-to-understand format. Additionally, there is a need to avoid including too many broken and unnecessary links, especially those with many advertisements.

A teaching textbook is an important carrier of a comprehensive compilation of course content [27] and has been found to be frequently mentioned in negative reviews. As suggested by DeLone and McLean [28], information quality can positively affect learners' satisfaction and their intention to learn. The positive effect of textbooks, especially those good textbooks that are written by instructors, are considered to be valuable since textbook use benefits learners as references of standard sources [29]. To improve programming textbook design, the textbooks should contain corresponding knowledge points that are helpful and 
have reference value for learners in solving homework problems. Second, sufficient information should be contained in textbooks to cover the target knowledge of courses. Additionally, realworld information should be included to avoid textbooks being over-theoretical to enhance practical value. A new form of textbooks, that is, interactive textbooks, refers to "material involving less text, and instead of having extensive learning-focused question sets, animations of key concepts, and interactive tools (p. 2) [30]." Research indicates that learners who spare more effort in activities using interactive textbooks tend to achieve better performance in examination in comparison to those using traditional print textbooks. Thus, MOOC providers and instructors can consider providing self-written textbooks in an interactive format.

Additionally, we reveal MOOC learner complaints across MOOCs with varied grades. Results indicate that for high-graded MOOCs, learner complaints relate primarily to problem-solving, practices, and programming textbooks, whereas learners of low-graded MOOCs are frequently annoyed by issues about grading and course quality. Accordingly, providers of high-graded MOOCs are suggested to promote problem-solving efficiency and quality of practices and programming textbooks; providers of low-graded MOOCs should pay more attention to course quality and grading improvement.

The correlations among topics indicate the nature of MOOC learner (dis)satisfaction. For example, grading, as the most common negative topic, relates closely with programming textbooks and problem-solving and practices. An examination of specific review comments indicates that many learners complain that the grading of assignments and practices by autograders is often inconsistent with the knowledge points described in textbooks, causing confusion and uncertainties. Therefore, learners who write about grading tend to complain as well about programming textbooks or problem solving and practices. The graphical topic correlation analysis offers corpus-level implications about organizational structures and facilitates the understanding of why learners complain.

In sum, our study helps understand what causes MOOC learners to be dissatisfied and provides actionable suggestions on MOOC management. To improve MOOC learner satisfactions, MOOCs and online review websites can exploit automatic text mining methods like STM. Considering the dynamic nature of learner demands, MOOC managers ought to be constantly aware of learners' learning experiences and feedback derived from their reviews. By integrating time, MOOC properties, and learner characteristics into topic models, managers are able to trace learner (dis)satisfaction dynamics and understand their MOOCs' strengths and weaknesses.

This study has limitations. Firstly, we used reviews of programming MOOCs from one platform. For the purpose of result generalization, there is a need to extensively use MOOCs of different subjects and from various platforms to enhance the model's effectiveness and ability. Considering that courses of different subjects might have different characteristics, further comparisons of topics hidden in course reviews of different subjects should also be conducted. Secondly, we included review extremities and MOOC grades as STM covariates. Future work is suggested to consider more covariates, for example, learner characteristics, to allow more fine-tuned insights into MOOC development.

\section{CONFLICTS OF INTEREST}

The authors declare they have no conflicts of interest.

\section{AUTHORS' CONTRIBUTION}

Xieling Chen contributed in the design and methodology of the study. Gary Cheng and Haoran Xie contributed in data analysis and interpretation. Guanliang Chen and Di Zou contributed in manuscript preparation.

\section{ACKNOWLEDGMENTS}

The research described in this article has been supported by the One-off Special Fund from Central and Faculty Fund in Support of Research from 2019/20 to 2021/22 (MIT02/19-20), the Interdisciplinary Research Scheme of the Dean's Research Fund 2019-20 (FLASS/DRF/IDS-2) and the Research Cluster Fund (RG 78/2019-2020R) of The Education University of Hong Kong, General Research Fund (No. 18601118) of Research Grants Council of Hong Kong SAR, and Lam Woo Research Fund (LWI20011) of Lingnan University, Hong Kong.

\section{REFERENCES}

[1] K.F. Hew, X. Hu, C. Qiao, Y. Tang, What predicts student satisfaction with MOOCs: a gradient boosting trees supervised machine learning and sentiment analysis approach, Comput. Educ. 145 (2020), 103724.

[2] S. Molinillo, A. Fernández-Morales, J.L. Ximénez-de-Sandoval, A. Coca-Stefaniak, Hotel assessment through social mediaTripAdvisor as a case study, Tour. Manag. Stud. 12 (2016), $15-24$.

[3] X. Chen, D. Zou, G. Cheng, H. Xie, Detecting latent topics and trends in educational technologies over four decades using structural topic modeling: a retrospective of all volumes of Computers \& Education, Comput. Educ. 151 (2020), 103855.

[4] F.F. Lubis, Y. Rosmansyah, S.H. Supangkat, Topic discovery of online course reviews using LDA with leveraging reviews helpfulness, Int. J. Electr. Comput. Eng. 9 (2019), 426-438.

[5] S. Liu, X. Peng, H.N.H. Cheng, Z. Liu, J. Sun, C. Yang, Unfolding sentimental and behavioral tendencies of learners' concerned topics from course reviews in a MOOC, J. Educ. Comput. Res. 57 (2019), 670-696.

[6] M.E. Roberts, B.M. Stewart, D. Tingley, STM: R package for structural topic models, J. Stat. Softw. 10 (2014), 1-40.

[7] N. Hu, T. Zhang, B. Gao, I. Bose, What do hotel customers complain about? Text analysis using structural topic model, Tour. Manag. 72 (2019), 417-426.

[8] K.F. Hew, Promoting engagement in online courses: what strategies can we learn from three highly rated MOOCS, Br. J. Educ. Technol. 47 (2016), 320-341.

[9] X. Chen, J. Chen, G. Cheng, T. Gong, Topics and trends in artificial intelligence assisted human brain research, PLoS One 15 (2020), e0231192.

[10] B.G. Gameel, Learner satisfaction with massive open online courses, Am. J. Distance Educ. 31 (2017), 98-111. 
[11] K. Popper, The logic of scientific discovery, Routledge, London and New York, 2005.

[12] S. Ackroyd, J.A. Hughes, Data collection in context, Longman Group UK Ltd., London, UK, 1992.

[13] X. Peng, Q. Xu, Investigating learners' behaviors and discourse content in MOOC course reviews, Comput. Educ. 143 (2020), 103673.

[14] A. Ezen-Can, K.E. Boyer, S. Kellogg, S. Booth, Unsupervised modeling for understanding MOOC discussion forums: a learning analytics approach, Proceedings of the Fifth International Conference on Learning Analytics and Knowledge, Associtation for Computing Machinery, New York, USA, 2015, pp. 146-150.

[15] X. Peng, S. Liu, Z. Liu, W. Gan, J. Sun, Mining learners' topic interests in course reviews based on like-LDA model, Int. J. Innov. Comput. Inf. Control. 12 (2016), 2099-2110.

[16] D.M. Blei, Probabilistic topic models, Commun. ACM 55 (2012), 77-84.

[17] D.M. Blei, A.Y. Ng, M.I. Jordan, Latent dirichlet allocation, J. Mach. Learn. Res. 3 (2003), 993-1022.

[18] M.E. Roberts, B.M. Stewart, D. Tingley, C. Lucas, J. Leder-Luis, S.K. Gadarian, et al., Structural topic models for open-ended survey responses, Am. J. Pol. Sci. 58 (2014), 1064-1082.

[19] A. Garcia-Rudolph, S. Laxe, J. Saurí, M.B. Guitart, Stroke survivors on twitter: sentiment and topic analysis from a gender perspective, J. Med. Internet Res. 21 (2019), e14077.

[20] R.I. Chang, Y.H. Hung, C.F. Lin, Survey of learning experiences and influence of learning style preferences on user intentions regarding MOOCs, Br. J. Educ. Technol. 46 (2015), 528-541.

[21] A. Ramesh, S.H. Kumar, J. Foulds, L. Getoor, Weakly supervised models of aspect-sentiment for online course discussion forums, Proceedings of the 53rd Annual Meeting of the Association for Computational Linguistics and the 7th International Joint Conference on Natural Language Processing, vol. 1: Long Papers, Association for Computational Linguistics, Beijing, China, 2015, pp. 74-83.

[22] X. Chen, D. Zou, H. Xie, G. Cheng, What Are MOOCs Learners' Concerns? Text Analysis of Reviews for Computer Science
Courses, in: Y. Nah, C. Kim, S.Y. Kim, Y.S. Moon, S.E. Whang (Eds.), Database Systems for Advanced Applications, DASFAA 2020 International Workshops, DASFAA 2020, Springer, Cham, 2020, pp. 73-79.

[23] K.F. Hew, Unpacking the strategies of ten highly rated MOOCs: implications for engaging students in large online courses, Teach. Coll. Rec. 120 (2018), 1-40.

[24] N.A. Albelbisi, Development and validation of the MOOC success scale (MOOC-SS), Educ. Inf. Technol. 25 (2020), 4535-4555.

[25] M. Yang, Z. Shao, Q. Liu, C. Liu, Understanding the quality factors that influence the continuance intention of students toward participation in MOOCs, Education. Tech. Research Dev. 65 (2017), 1195-1214.

[26] J.M. Kevan, M.P. Menchaca, E.S. Hoffman, Designing MOOCs for success: a student motivation-oriented framework, Proceedings of the Sixth International Conference on Learning Analytics \& Knowledge, Association for Computing Machinery, Edinburgh, UK, 2016, pp. 274-278.

[27] C. Zhang, S. Yi, B. Rao, An empirical study on the satisfaction of new form textbook based on ACSI, Proceedings of the 5th International Conference on Distance Education and Learning, Association for Computing Machinery, Beijing, China, 2020, pp. 128-132.

[28] W.H. DeLone, E.R. McLean, The DeLone and McLean model of information systems success: a ten-year update, J. Manag. Inf. Syst. 19 (2003), 9-30.

[29] P. Adamopoulos, What makes a great MOOC? An interdisciplinary analysis of student retention in online courses, Proceedings of the 34th International Conference on Information Systems, ICIS 2013, AIS, Milano, Italy, 2013.

[30] A.D. Edgcomb, F. Vahid, R. Lysecky, A. Knoesen, R. Amirtharajah, M.L. Dorf, Student performance improvement using interactive textbooks: a three-university cross-semester analysis, 2015 ASEE Annual Conference \& Exposition, Seattle, Washington, 2015, pp. 26.1423.1-26.1423.17. 